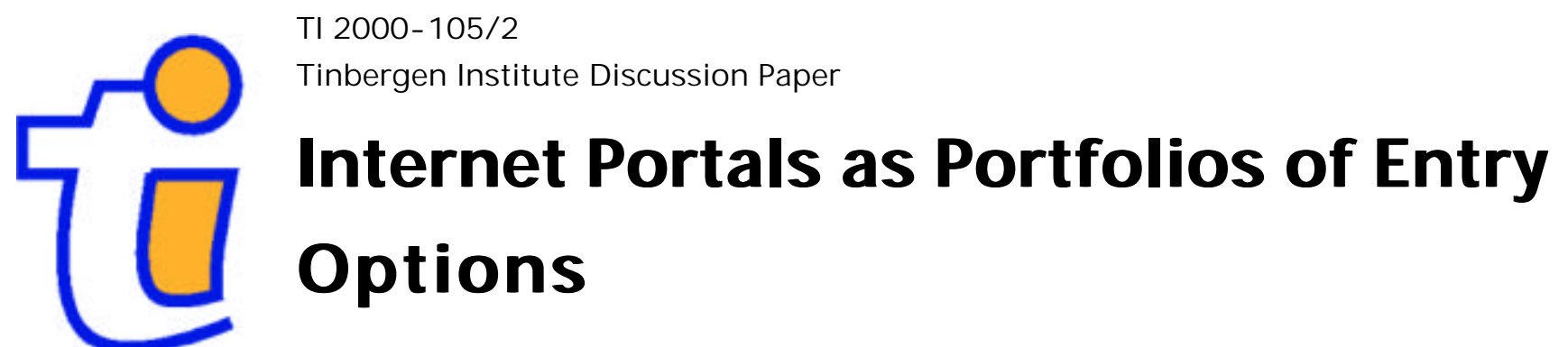

Enrico Perotti

Silvia Rossetto 
Tinbergen Institute

The Tinbergen Institute is the institute for economic research of the Erasmus Universiteit Rotterdam, Universiteit van Amsterdam and

Vrije Universiteit Amsterdam.

Tinbergen I nstitute Amsterdam

Keizersgracht 482

1017 EG Amsterdam

The Netherlands

Tel.: +31.(0)20.5513500

Fax: $\quad+31 .(0) 20.5513555$

Tinbergen I nstitute Rotterdam

Burg. Oudlaan 50

3062 PA Rotterdam

The Netherlands

Tel.: $\quad+31 .(0) 10.4088900$

Fax: $\quad+31 .(0) 10.4089031$

Most TI discussion papers can be downloaded at

http://www.tinbergen.nl 


\title{
Internet Portals as Portfolios of Entry Options*
}

\author{
Preliminary Draft
}

\author{
Enrico Perotti \\ Silvia Rossetto \\ University of Amsterdam and CEPR University of Amsterdam
}

November 8, 2000

\footnotetext{
${ }^{*}$ We would like to thank Frank De Jong for his comments and encouragement. We are also grateful to Jean Tirole and Bruno Biais for very helpful insights. We thank seminar participants at the Tinbergen Institute of Amsterdam, the TMR 2000 meeting in Barcelona and the EFA00 meeting. The second author acknowledges financial support from Scuola Superiore S.Anna. We retain sole responsibility for all remaining errors. Address for correspondence: Silvia Rossetto, Tinbergen Institute, Keizersgracht 482, NL-1017 EG Amsterdam, The Netherlands. e-mail: rossetto@tinbergen.nl
} 


\begin{abstract}
We investigate the valuation of platform investment, such as a software operating system or an internet portal webpage. Platform investment is the creation of an innovative distribution and production infrastructure which increases access to customers; as a result it reduces entry costs in related products. Relative to conventional producers, firms built around platforms enjoy enhanced entry options in uncertain market segments, to be exercised at the optimal strategic timing. When the platform grants a strong strategic advantage, the innovator firm can optimally choose the timing of entry when its strategic gain exceeds the value of the waiting option; in case of weaker advantage, the platform firm enters just before its competitor would. In a context of increased uncertainty, the relative value of platform to traditional strategies increases; the value of waiting to invest rises, but the value of platforms increases even more. In some cases, platform can reduce entry by making parallel monopoly sustainable.
\end{abstract}




\section{Introduction}

This paper seeks to understand the possible foundations of notion of platform investment, a concept which has achieved mainstream interest in management science (for a survey see Kogut and Kulatilaka (1994)) and relate it to the strategic real option literature, a methodology to price growth opportunities.

Platform investment refers to the establishment of a broad logistic infrastructure which allows easier entry in related product segment and improve market responsiveness. There are well-documented examples of platform investment which have resulted in significant market advantages for the investing firms. However, to date there are hardly any theoretical treatment of the implied strategic and valuation issues.

An example of a platform is a computer operating system. The explosion of the PC market was based on standardized software applications, which were made on compatible thanks to the extreme diffusion of the DOS-Windows operating system. The company which controls the operating system is in an advantageous position to develop subsequent software applications compatible with the platform, and enjoy an immediate advantage with users. ${ }^{1}$

Nowadays an even more central role is played by internet, a web of interconnected computers which allows workers to perform complex coordinated tasks and exchanging information in real time. As Internet is a global network, owners of frequently visited sites (as hubes, or "portals") enjoy a tremendous distributional capacity for information, services and product sales.

Such horizontal internet portals, either in closed systems (such as AOL) or

\footnotetext{
${ }^{1}$ There are other examples of platform investment. Renowned cases are Boeing's investment in information technology and communications network processes that integrate suppliers and manufacturing plants with designers, considerably facilitating new product development. This pattern has been much adopted in the car industry: the number of their subcontractors has been significantly reduced but the productive process has become closely integrated via a common communication and productive platform. Another classic example is the information and distribution infrastructure built by Wal-Mart, targeted at rapid collection of information on customer purchases at individual shops connected with a rapid-response retail distribution system (Khanna and Tice (2000)). The rapid integration in the communication and financial service industries have been predicated on the presence of strong synergies in distribution, allowing easier entry in new products. Thus platform investment concerns the creation of intermediate infrastructure common to several types of future productive activities; this logistic infrastructure is not only incorporated in physical assets but also in market knowledge, customer information and access.
} 
open access (such as search engines such as Yahoo or general retail outlets such as Amazon) are other example which fits the concept of platform investment. ${ }^{2}$ These companies have gained a primary position as a focal point in a network by offering a desirable service and building a strong brand name on internet, while learning much about their customers' characteristics. This "informed client database" and name recognition has created a basis for dramatic potential expansion in offering more services via the net. A portal can be seen as a hub in the network, a point of entry connected with relevant information or access to products. It lowers the cost of reaching customers and thus the cost of entry in new market segments.

This paper builds a model of the value of the associated strategic advantages which allows us to compare the relative valuation of such "platform stocks" versus conventional producers. In particular, the analysis allows to study the impact of demand uncertainty, on strategy and valuation. Unlike the strong results of the network externalities and switching cost literature (see Klemperer (1995) for a review) in our model the innovator-early mover does not capture the market completely.

The strategic implications of platform investment place its analysis in the context of the literature on strategic growth options, which examines the impact of investment to gain comparative advantages vis-à-vis competitors. The commitment of irreversible investment may confer strategic advantages as a result of lower capacity costs (Dixit (1980)), operating costs (Kulatilaka and Perotti (1998)) or faster timing-to-market (Kulatilaka and Perotti (forthcoming 2000)). In all of these models, strategic investment increases market share and profit growth at the expense of competitors; the investing firm strengthens its postentry position, gaining market share, and may discourage entry by competitors (Dixit (1980) and Lambrecht and Perraudin (1997)). In our approach we contrast platform investment to a traditional investment in productive capacity. This allows us to compare the valuation of platform firms relative to the value of established producers (old economy). ${ }^{3}$ We therefore explicitly treat entry in

\footnotetext{
${ }^{2}$ Vertical portals are webpages with very focused market content, such as myflowers.com. Amazon is an example of an originally vertical portal specialized in book sales which has extended itself into a broad platform (a horizontal portal), selling via internet all sorts of products.

${ }^{3}$ In related work we are studying why strategic analysis allows us to suggest that established firms may resist entry in new products because of the cross-effect with their traditional product
} 
related segment, which require us to consider cross effects.

We model the advantage gained by a platform investment as a greater ease of entry (lower fixed costs) in markets for related products. The construction of a logistic platform can thus be described as the acquisition of a set of strategic entry options. ${ }^{4}$ Another possible advantage of a platform is the lower costs of access to customers, and thus a lower marginal cost. Our focus on fixed cost allows us to concentrate more on the timing of entry rather than market share.

The basic model we develop is as follows. A firm considers a platform investment in a sector in which there is also a traditional incumbent. Demand is uncertain and evolves stochastically over time. Suppose that the new firm has the opportunity to make a platform investment, which leads to produce a differentiated product but also offers the option to enter later at a reduced cost in a related market segment.

The approach used here is related to the one used in Smets (1991): when market demand is low, firms prefer to wait to enter (the option of waiting to invest is more valuable than the higher profits gained), although this carries the risk to end up being a follower. As the market expands, the attractiveness of being first increases, until at a certain point the firm decides to enter. (See also Grenadier (1996) for an application to the real estate industry). Undertaking an investment under uncertainty over future demand incurs the opportunity cost of investing prior to obtaining more information (McDonald and Siegel (1986)); thus the strategic value of early investment must be compared with the investment cost plus the option value of waiting (Kulatilaka and Perotti (1998)). However, the approach in this paper our model is more complex because of cross effect of demand due to related products.

We show that depending on the degree of strategic advantage that the platform offers, the innovator decides for two different entry strategies. If the difference between the investment costs is not large, the platform firm enters just before the competitor would, inducing him to postpone its cross-entry. In this case we say that the platform firm "owns" the option to enter as leader over a certain range of demand levels, but it is forced to exercise it before its optimal timing in order to pre-empt its competitor. If the investment cost difference is

line. This raises the issues whether internet firms should be independent of existing brand name producers.

${ }^{4}$ This notion is related to the concept of a core capability or a platform investment (see Baldwin and Clark (2000) and Kogut and Kulatilaka (1994)). 
significant, the platform firm knows that the traditional firm would not enter as leader because the period of time in which it can have a leader position is not enough long to compensate for its high investment cost. In this case the platform firm has a de facto "monopoly" on the option to enter, in the sense that it can wait until the optimal entry timing without fearing pre-emption. Its optimal entry timing trades off the value of the waiting-to-invest option against the higher profits from cross-entry, taking into account the preemption effect.

In the comparative statics we focus on the effects of uncertainty (which produces the greatest difference between option-based and NPV-based models of valuation). The effect of uncertainty on the strategic advantage and thus of the platform value is ambiguous, depending on which of two elements prevails: the higher the uncertainty the higher the value to wait, but at the same time the higher the expected profits in case of immediate cross entry. This last effect is due to two factors. First, high uncertainty increases the value of the strategic entry option more than the option value of not investing. As in Kulatilaka and Perotti (1998), this is because in an oligopolistic market structure prices increase with demand; therefore, profits are endogenously convex in demand as firm raise their margin. Because of this convexity, a mean-preserving increase in uncertainty favors investment in the strategic growth option over the waiting option. ${ }^{5}$ Second, it increases the time period in which the firm acts as monopolist in the entry decisions without facing any risk of entry by the competitor. However, the general result is unambiguous: greater uncertainty increases the strategic advantage of the platform and increases the value of the platform relative to traditional investment. Also in absolute terms we show that the higher is uncertainty, the higher is the platform value.

The next section presents the market equilibrium under Cournot competition. ${ }^{6}$ In the third section we determine the entry strategies of the platform firm when it enters in the competitor's product segment. Section fourth analyzes the

\footnotetext{
${ }^{5}$ This result cannot be directly compared to the apparently contrary implications on the relative value of the waiting-to-invest option McDonald and Siegel (1986). In the context of imperfect competition, investment has an impact on market structure and marginal profitability (Kulatilaka and Perotti (1998), Grenadier (1996)), creating a strong incentive for early investment, while in the traditional literature real option the underlying market is not affected by the investment.

${ }^{6}$ Price competition does not result an interesting issue since in this case neither a platform firm nor a traditional firm ever cross-enters in each other's market segment, so the platform has no value.
} 
volatility effect on the entry strategy of the platform. In section 5 we compute the entry strategy. We offer at the end some concluding thoughts and ideas for further work.

\section{The basic model}

We consider two firms $i$ and $j$ competing in real time. The first one is an incumbent which has invested in a traditional, specialized investment (T); the other one, the innovator, consider the possibility to invest in a platform infrastructure (I). While a platform may cover several market segments, we set this number to one for simplicity, to obtain a lower bound valuation for a platform vis-a-vis a traditional producer. More generally platform may grants entry options in multiple market segments

We assume that firms have complete information about the market and the cost structures. ${ }^{7}$ We also assume that there are only two differentiated products, indexed by 1 and 2. The inverse market demand functions for the two products are:

$$
\begin{aligned}
& p_{1}=\gamma-\left(q_{1 i}+q_{1 j}\right)-a\left(q_{2 i}+q_{2 j}\right) \\
& p_{2}=\gamma-a\left(q_{1 i}+q_{1 j}\right)-\left(q_{2 i}+q_{2 j}\right)
\end{aligned}
$$

Note that the two product are partial strategic substitutes (see ? for a definition of strategic substitutes); the parameter $a$ represents the intensity of substitution, and ranges from 0 (no substitutability) to 1 (identical products).

Specialized entry in any market requires the investment of an amount I; investment in a platform costs $K$. In addition, a platform firm would pay $I_{P}$ as the incremental investment to enter in any market segment, with $I_{P}<I<$ $I_{P}+K$. Thus there is an extra cost to build a platform, but this allows easier cross-entry thereafter. ${ }^{8}$

Firms that compete in the same market engage in Cournot competition. When each firm produces a differentiated product, they act as monopolists in

\footnotetext{
${ }^{7}$ One example of strategic entry under imperfect information is analyzed in Lambrecht and Perraudin (1999).

${ }^{8}$ This assumption sets our analysis apart from most of the literature on entry in strategic entry such as Smets (1991), Dixit (1980) and Huisman and Kort (1999).
} 
their own market, though their margins are influenced by the substitution effect among products.

The intercept of the demand function, $\gamma$, represents the size of market demand. Demand size is uncertain and evolves stochastically over time. We assume that it follows a Geometric Brownian Motion:

$$
\frac{d \gamma}{\gamma}=\frac{1}{2}\left(\mu-\frac{1}{2} \sigma^{2}\right) d t+\frac{1}{2} \sigma d z
$$

In the specification, $\sigma$ appears as parameter both in the volatility and in the drift term of the demand process, in order to isolate the effect of demand uncertainty from its drift. In comparative statistic we will we carry out a meanpreserving-spread analysis in the sense of Rotschild and Stiglitz (1970). To this goal, we define $\alpha=\frac{2 \mu-\sigma^{2}}{2}$ so that we can rewrite the market process, (3), as:

$$
\frac{d \gamma}{\gamma}=\frac{1}{2} \alpha d t+\frac{1}{2} \sqrt{2(\mu-\alpha)} d z
$$

This formulation allows us to perform a mean preserving spread on the distribution of demand by varying its demand volatility while adjusting the drift so that there is no change in expected demand.

Oligopolistic profits under Cournot competition are convex in demand. We thus define $\gamma^{2} \equiv \theta$. We can express the evolution of $\theta$ through Ito's Lemma as a Geometric Brownian motion:

$$
\frac{d \theta}{\theta}=\mu d t+\sigma d z
$$

We see later that $\theta$ is linearly related to firm profits, and $\sigma$ is closely related to their volatility.

To ensure finite valuations, we assume that $\mu<r$, where $r$ is the discount factor. We also assume that $\alpha<\mu(<r)$ to ensure $\sigma^{2}>0$.

We first evaluate the value of a "platform" firm and then compare it with the value of the traditional firm. ${ }^{9}$

\footnotetext{
${ }^{9}$ As the market scope is just dimensional, the platform will cover only a line. A later version will consider a broader definition of a platform.
} 


\section{II.1 Product Market Interactions}

Initially the platform firm operates in a different product segment from the competitor. This leads to a parallel differentiated monopoly. The associated profit flow (see the Appendix A.1.1) is:

$$
\prod_{i, t}=\prod_{j, t}=\frac{1}{(a+2)^{2}} \theta_{t} \equiv M \theta_{t}
$$

and its associated valuation of the firm is:

$$
E\left[\int_{0}^{\infty} M \theta_{t} e^{-r t} d t\right]=\frac{M}{r-\mu} \theta_{t}
$$

This is the discounted stream of expected profits when the underlying expected profit growth is equal to $\mu$ and there is no change in market structure.

Both firms have the possibility to enter in the competitor's market segment: for the traditional firm the cross entry will cost $I$, while for the platform firm the cost will be $I_{P}$ (with $I_{P}<I$ ). If both firms cross-enters in each other's market (parallel duopoly), the profit flow and the expected present value are (see Appendix A.1.1):

$$
\begin{gathered}
\prod_{i, t}=\prod_{j, t}=\frac{2}{9} \frac{1}{a+1} \theta_{t} \equiv D \theta_{t} \\
E\left[\int_{0}^{\infty} D \theta_{t} e^{-r t} d t\right]=\frac{D}{r-\mu} \theta_{t}
\end{gathered}
$$

When a firm cross-enters as first (we term this situation an "asymmetric duopoly"), the rival may prefer at first to wait to enter, if the waiting to invest option is more valuable than the higher profits from symmetric duopoly. ${ }^{10}$ In this case the first firm to cross-enter enjoys higher asymmetric profits (being a monopolist in their own segment and a duopolist in the second). These extra profits are just temporary: as demand increases the other firm will find convenient to exercise the option to enter, and the market outcome will be in a

\footnotetext{
${ }^{10}$ In a static framework, since profits are higher under parallel monopoly $(M>D)$, both firms would prefer to maintain a collusive arrangement avoiding entry under a threat of an immediate cross-entry in case the competitors enters as first. However, in our dynamic framework this is not credible.
} 
parallel duopoly in both product. However, the option to enter as first is clearly valuable. As we will see, this is one of the advantages of building a platform.

We define as asymmetric duopoly the case in which one firm operates in both segments and the other in just one). The profits flow and its expected present value for the firm present in both markets are (see Appendix A.1.2):

$$
\begin{gathered}
\prod_{i, t}=\frac{1}{36} \frac{13-5 a}{1+a} \theta_{t} \equiv L \theta_{t} \\
E\left[\int_{0}^{\infty} L \theta_{t} e^{-r t} d t\right]=\frac{L}{r-\mu} \theta_{t}
\end{gathered}
$$

while the other firm earns:

$$
\prod_{i, t}=\frac{1}{9} \theta_{t} \equiv F \theta_{t}
$$

with an expected present value of:

$$
E\left[\int_{0}^{\infty} F \theta_{t} e^{-r t} d t\right]=\frac{F}{r-\mu} \theta_{t}
$$

Note that these profits are equal to profits under Cournot competition, as the entrant produces less in its original market for the increased cross-effect.

Because $0<a<1$, a firm always prefers to be in both market segments if its the competitor produces just in one, while it would prefer to be monopolist in just one market than being duopolist in both. However, the option to crossenter as first grants temporarily higher returns. ${ }^{11}$ This can be summarized with the following relations: $F \leq D \leq M \leq L$.

Notice that since $0<a<1, L-M$ and $D-F$ are decreasing functions of a. Moreover, $L-M<D-F$ : the profit increment as a result of cross-entry is never larger than the profit increment of a follower cross-entrant. ${ }^{12}$ Another

\footnotetext{
${ }^{11}$ Under some parameters values, this creates a sort of prisoner's dilemma in entry strategy. Firms would like to be able to mutually commit not to enter in each other's market, but such a commitment is not credible: there is a temptation to enter.

${ }^{12}$ This difference at first increases as $a$ rises (diminishing the differentiation) and subsequently it diminishes, vanishing when $a=1$ (no product differentiation). This relation will be useful later for our conclusions.
} 
result is that $M<L-M$ : entering the second market leads to less than double monopoly profits. Finally $L-M-F<0$ : entering as leader leads to an increase in profits lower than profits the follower that remains in only one market.

\section{The dynamic game}

In order to evaluate the platform firm we first analyze the optimal entry strategies of the two firms. We can then compute the value of the platform and traditional investment then the firms values.

For low levels of demand, there is no incentive for immediate cross entry in the other product, so both firms remain as monopolists in their own market segment (although their profits are influenced by the substitution among products).

However, as demand rises, the attractiveness of entry in the second segment increases. Since the innovating firm controls a platform, it can enter in the first product with a lower incremental cost than the traditional producer. Intuitively, it will have a lower threshold for entry.

We show later that in equilibrium the traditional firm is always a follower in the entry game. As a result, the platform firm enjoys for a certain time interval a sort of monopoly on the option to enter as leader, knowing that the competitor would not move first. This is the crucial strategic entry advantage for the platform firm.

We define the entry threshold of the platform firm as $\theta_{I}^{*}$. At this threshold the profits flow of the innovator will be by the sum of profits in the shared market plus monopoly profits in its market segment (see equation (11)), while the traditional producer earns duopolistic profits in its segment(13).

Also the traditional firm will cross-enters (see equation (8)) as demand rises enough. We define this subsequent entry threshold as $\theta_{T}^{* *}$. This value affects the value of the strategic entry option by the platform firm, which is a function of the expected time of follower entry. We will see that this expected entry time is not trivial to compute. 


\section{III.1 Entry of the traditional firm}

We solve the game backward. We first assume that the innovator (the platform) has already cross-entered, and compute when the traditional firm would follow. ${ }^{13}$ Subsequently, we check that the entry strategy for the innovator leads it to enter as first.

Let $\theta=\theta_{T}^{* *}$ be the threshold level of demand such that when $\theta \geq \theta_{T}^{* *}$ the traditional firm is willing to cross-enter as first in the other market. At that point the present value of the traditional firm is worth $\frac{D}{r-\mu} \theta-I$, where $I$ is its own cost of entry. For $\theta<\theta_{T}^{* *}$, traditional firm waits until the first passage in time of the threshold value; during this interval it earns $\frac{F}{r-\mu} \theta$. Thus the expected present value of its cross-entry investment is given by:

$$
E\left[\int_{0}^{T^{* *}} e^{-r t} F \theta_{t} d t\right]+E\left[e^{-r T^{* *}}\right]\left[\frac{D}{r-\mu} \theta_{T}^{* *}-I\right]
$$

where $T^{* *}$ is the expected time to reach the point $\theta_{T}^{* *}$ starting from $\theta$. Following Dixit and Pindyck (1994) and Harrison (1985), we solve this optimal stopping problem. $T^{* *}$ equals:

$$
T_{T}^{* *}\left(\theta_{t}\right)=-\frac{\beta}{r} \ln \frac{\theta_{t}}{\theta_{T}^{* *}}
$$

where $\beta=\frac{1}{2}-\frac{\mu}{\sigma^{2}}+\sqrt{\left(\frac{\mu}{\sigma^{2}}-\frac{1}{2}\right)^{2}+2 \frac{r}{\sigma^{2}}}>1 . \beta$ is thus negatively related to market and profit volatility: more precisely when volatility tends to $0, \beta$ tends to infinity while when volatility tends to infinity, $\beta$ tends to 1 . As $\beta$ inversely related both $\sigma$ and $\mu$ (respectively profit and demand uncertainty), in many cases we will use $1 / \beta$ as a natural metric for uncertainty.

The expected value of the second firm is:

$V_{T}\left(\theta_{t}\right)=\left\{\begin{array}{lll}\frac{F \theta_{t}}{r-\mu}\left[1-\left(\frac{\theta_{t}}{\theta_{T}^{* *}}\right)^{\beta-1}\right]+\left(\frac{\theta_{t}}{\theta_{T}^{* *}}\right)^{\beta}\left[\frac{D}{r-\mu} \theta_{T}^{* *}-I\right] & \text { if } & \theta_{t}<\theta_{T}^{* *} \\ \frac{D}{r-\mu} \theta_{t}-I & \text { if } & \theta_{t} \geq \theta_{T}^{* *}\end{array}\right.$

while the optimal $\theta$ at which the traditional firm will enter is given by:

\footnotetext{
${ }^{13}$ We will show later that this is alaways the case in any equilibrium with entry, due to the entry cost difference.
} 


$$
\theta_{T}^{* *}=\frac{\beta}{\beta-1} \frac{I}{\frac{D-L}{r-\mu}}=\frac{\beta}{\beta-1} \frac{I}{\frac{1-a}{9(1+a)(r-\mu)}}
$$

\section{III.2 Entry of the platform firm}

The next step is to determine the cross-entry point for the platform firm. This approach follows Smets (1991) and Grenadier (1996), in which a duopoly a firm would enter as soon as he prefers to be a leader rather then a follower.

In such an entry game with symmetric firms, there is an ambiguity as to which firm will enter as first. In our case, due to the different investment costs, the platform firm enjoys a period of monopoly on the choice to cross-enter as leader, since it knows that the traditional firm would not yet find it profitable to enter. In this period of a "monopoly on the option to enter as leader" the innovator exercises optimally this entry option as leader by comparing the value of waiting to enter (and thus avoiding losses) to the higher profits after entry. Note the analogy in this case with the classic "monopolistic" real option of McDonald and Siegel (1986). A difference here is that entry effects prices and market shares.

We first study the case of a pure monopoly on the option to enter as leader, subsequently we check the effect of possible entry by the competitor.

Proposition 1 If the innovator firm had a pure monopoly on the option to cross-enter as first, it would enter when

$$
\frac{I_{P}}{I}<\left(\frac{1}{\beta} \frac{L-M}{L-D}\right)^{\frac{1}{\beta-1}} \frac{L-M}{D-F}
$$

at $\theta_{m}^{*}=\frac{\beta}{\beta-1} \frac{I_{P}(r-\mu)}{L-M}$.

Proof. See Appendix A.3 for a demonstration.

In case of pure monopoly on the option to cross-enter as first, the platform firm cross-enters only when the payoff of entering is superior to the one of remaining in a parallel monopoly. This true only when condition (18) is verified.

When this condition is verified in the interval $0 \leq \theta<\theta_{m}^{*}$ the innovator firm would prefer to wait. However, in general the innovator firm has no monopoly on the right to enter, so it has to take into consideration a possible entry by competitors. 
To determine the period over which the platform firm prefers to wait, we look under what condition the entry threshold in case of entry monopoly is higher than the entry threshold for the competing traditional firm.

This entry threshold is determined comparing the payoff of the traditional firm in case it enters as leader (which depends on the expected entry threshold for its competitor) and in case it enters as follower. We define as $\Delta_{T}(\theta)$ the difference of this two payoffs.

\section{Proposition 2 If}

$$
\frac{I_{P}}{I} \geq\left(\frac{5}{4} \frac{9^{-\beta} \beta}{4^{-\beta}-9^{-\beta}}\right)^{\frac{1}{\beta-1}}
$$

a traditional firm would cross-enter as first as soon as demand reaches $\sqrt{\theta_{T}^{*}}$, the smallest solution of $\Delta_{T}(\theta)=0$.

Proof. A traditional firm would enter in the other segment as first, as soon as the payoff of being a leader is higher than the payoff of being a follower, that is when:

$$
\begin{aligned}
& \frac{L \theta_{t}}{r-\mu}\left[1-\left(\frac{\theta_{t}}{\theta_{P}^{* *}}\right)^{\beta-1}\right]+\left(\frac{\theta}{\theta_{P}^{* * *}}\right)^{\beta} \frac{D}{r-\mu} \theta_{P}^{* *}-I \geq \\
& \frac{F \theta_{t}}{r-\mu}\left[1-\left(\frac{\theta_{t}}{\theta_{T}^{* *}}\right)^{\beta-1}\right]+\left(\frac{\theta_{t}}{\theta_{T}^{* * *}}\right)^{\beta}\left(\frac{D}{r-\mu} \theta_{T}^{* *}-I\right)
\end{aligned}
$$

where:

$$
\theta_{P}^{* *}=\frac{\beta}{\beta-1} \frac{I(r-\mu)}{D-L}
$$

which is the entry threshold of the platform firm as follower. The expression for $\theta_{P}^{* *}$ differs from (17) only by the different investment costs.

Rearranging we obtain:

$$
\Delta_{T}=(L-F) \theta_{t}-\left(\frac{L-D}{\theta_{P}^{* *^{\beta-1}}}+\frac{D-F}{\beta \theta_{T}^{*^{\beta-1}}}\right) \theta_{t}^{\beta}-I(r-\mu) \geq 0
$$


$\Delta_{T}$ is a concave function ${ }^{14}$, is negative when $\theta=0$ and has a maximum for positive values of $\theta$. Hence, the level of demand at which a traditional firm prefers to be a leader rather than follower is given by the $\theta$ that solves $\Delta_{T}(\theta)=0$ and for which $\frac{\partial \Delta}{\partial \theta}>0$.

This equation cannot be solved explicitly. However, we can define some features of $\Delta_{T}(\theta)=0 . \Delta_{T}(\theta)=0$ has solutions when its maximum is positive, which requires that:

$$
\frac{I_{P}}{I}>\left(\frac{5}{4} \frac{9^{-\beta} \beta}{4^{-\beta}-9^{-\beta}}\right)^{\frac{1}{\beta-1}}
$$

Since $\Delta_{T}(\theta)$ is concave, if the above condition is satisfied, $\Delta_{T}(\theta)=0$ has two real roots; the smallest one is the one for which $\frac{\partial \Delta}{\partial \theta}>0$. We indicate this $\theta$ as $\theta_{T}^{*}$.

When this condition is not satisfied $\Delta_{T}(\theta)$ is negative: the traditional firm prefers to be a follower rather than a leader for any demand values.

The economic implication is that if the investment cost difference is large the traditional entry firm has no incentive ever to cross-enter as leader because the platform would subsequently cross-enter too early to be able to reconvert the entry cost.

Corollary 3 The payoff to the platform firm of being a leader relative to being a follower, is always higher than this payoff for the traditional firm. Hence, the platform prefers to be a leader rather than a follower before the traditional firm.

Proof. This is a direct consequence of the investment cost differential.

We define the condition (19) as determining whether the platform grants a Strong Strategic Advantage or a Weak Strategic Advantage. We will next show that in the former case the platform grants a de facto monopoly on the entry-as-leader option over the range of optimal exercise, in the latter it needs to cross-enter before it would be optimal in order to pre-empt the traditional firm.

Proposition 4 (Strong strategic advantage with entry) When
$\frac{I_{P}}{I}<\left(\frac{1}{\beta} \frac{L-M}{L-D}\right)^{\frac{1}{\beta-1}} \frac{L-M}{D-F}$ and $\frac{I_{P}}{I}<\left(\frac{5}{4} \frac{9^{-\beta} \beta}{9^{-\beta}-4^{-\beta}}\right)^{\frac{1}{\beta-1}}$, the platform firm can

\footnotetext{
${ }^{14}$ The concavity is due to the fact that the advantage created by the platform leads to temporary market dominance. Note that in our model, the platform does not create eternal monopoly.
} 
behave de facto as a monopolist on the entry as leader option, and enters at $\theta_{m}^{*}=\frac{\beta}{\beta-1} \frac{I_{P}(r-\mu)}{L-M}$.

Proof. When $\frac{I_{P}}{I}<\left(\frac{1}{\beta} \frac{L-M}{L-D}\right)^{\frac{1}{\beta-1}} \frac{L-M}{D-F}$, the constant term of the option is positive thus the platform firm finds convenient to cross-enter because its payoff is higher than the payoff of remaining in a parallel monopoly.

When $\frac{I_{P}}{I}<\left(\frac{5}{4} \frac{9^{-\beta} \beta}{4^{-\beta}-9^{-\beta}}\right)^{\frac{1}{\beta-1}}$ the platform firm can behave de facto as a monopolist on the entry option because for the traditional firm entry as leader is not convenient.

Hence the platform firm enter at $\theta_{m}^{*}=\frac{\beta}{\beta-1} \frac{I_{P}(r-\mu)}{L-M}$.

Intuitively, the traditional firm wants to enter when the payoff of being a leader is higher than of being a follower, that is when $\Delta_{T}(\theta)>0$. However when the investment difference is large, it never gets the chance to be a leader, because for any demand levels $\Delta_{T}(\theta)<0$, the traditional firm would enjoy asymmetric profits as leader for too short a time or no time at all given the subsequent entry by the platform firm.

As depicted in Fig.1, a traditional firm would never cross-enter under the threat of a subsequent entry of the platform as follower: his payoff of being a leader rather than a follower $(L P)$ is always negative.

When uncertainty is not high (that is, under condition (18)), as the payoff of cross-entering is higher than that of a parallel monopoly, the platform firm has a valuable option to cross-enter. It exercises his option to cross-enter optimally at the point $M$, while the traditional firm will cross-enter as follower at the point $F$.

As a result, under strong strategic advantage the platform firm knows that the threat of the traditional firm to cross enter as first is inexistent, and so for a certain interval of demand values it can behave de facto as a monopolist on the option.

Proposition 5 (Strong Strategic Advantage with no entry) When $\frac{I_{P}}{I}>$ $\left(\frac{1}{\beta} \frac{L-M}{L-D}\right)^{\frac{1}{\beta-1}} \frac{L-M}{D-F}$ and $\frac{I_{P}}{I}<\left(\frac{5}{4} \frac{9^{-\beta} \beta}{4-\beta-9-\beta}\right)^{\frac{1}{\beta-1}}$, the platform firm, which can behave de facto as a monopolist on the entry as leader, prefers not to enter. As a result, the market remains in a parallel monopoly.

Proof. Under $\frac{I_{P}}{I}<\left(\frac{5}{4} \frac{9^{-\beta} \beta}{4^{-\beta}-9^{-\beta}}\right)^{\frac{1}{\beta-1}}$, the platform firm can behave de facto 
as a monopolist. But when $\frac{I_{P}}{I}>\left(\frac{1}{\beta} \frac{L-M}{L-D}\right)^{\frac{1}{\beta-1}} \frac{L-M}{D-F}$ it does not find convenient to cross-enters.

At the same time entry by the traditional firm would also be not convenient as it would lead to an early cross-entry by the platform firm, for which now entry is a dominating strategy.

It follows that the platform does not enter and both firm prefers to remain in parallel monopoly.

When uncertainty is high and the investment cost ratio is relatively small, the platform firm can still de facto behave as a monopolist, but at the same time as no incentive to invest in the other market because the expected profits would be lower than in the case of parallel monopoly. Hence the platform can be seen as a tool to avoid aggressive cross, as equilibrium which is less desirable in some cases than parallel monopoly.

Proposition 6 (Weak strategic advantage) When $\frac{I_{P}}{I}>\left(\frac{5}{4} \frac{9^{-\beta} \beta}{4^{-\beta}-9^{-\beta}}\right)^{\frac{1}{\beta-1}}$, the platform firm enters just at the right time to pre-empt the traditional firm, that is, before the traditional firm would cross-enter as first. This is for the lowest demand level $\theta$ that solves $\Delta_{T}(\theta)=0$.

Proof. When $\frac{I_{P}}{I}>\left(\frac{5}{4} \frac{9^{-\beta} \beta}{4^{-\beta}-9^{-\beta}}\right)^{\frac{1}{\beta-1}}$, the traditional firm would enter as soon as $\theta>\theta_{T}^{*}$ such that $\Delta\left(\theta_{T}^{*}\right)=0$.

To demonstrate that the platform firm would cross-enter at $\theta_{T}^{*}$ we have to take into consideration the following elements:

- due to the lower inferior investment cost, a platform firm prefers already to be a leader rather than a follower (see Corollary 3 ).

- when the traditional firm cross-enters as leader, it must enjoy asymmetric profits for a certain period, that is $\theta_{T}^{*}<\theta_{P}^{* *}$ otherwise the traditional firm would not cross enter; since the platform firm would immediately follow.

- given $L-M<D-F, \theta_{P}^{* *}<\theta_{m}^{*}$.

It follows that $\theta_{T}^{*}<\theta_{m}^{*}$, that is, the traditional firm would enter before it is optimal for the platform firm to cross-enter as a monopolist. Hence platform firm is forced to cross-enter at $\theta_{T}^{*}$, a level of demand at which it would prefer to retain the option to wait to invest a bit longer. 
Under weak strategic advantage, for demand values immediately below $\theta_{T}^{*}$, the payoff of being a leader for the platform firm is higher than the payoff of being a follower, but not higher than the value of the waiting-to-enter option. In this interval, the platform firm can still choose to wait because the threat of the competitor's cross-entry is not credible. However, because at $\theta_{T}^{*}$ the traditional firm would certainly cross-enter, the platform firm will cross enter just before $\theta_{T}^{*}$, since it prefers to be a leader rather than a follower. In Fig. 2, the traditional firm for some demand values has a positive payoff being a leader relatively to being a follower: it would enter at $T$, the point where the payoff of being leader (LP) crosses the payoff of being a follower (FO). The platform firm, if it could choose, would enter at $M$ where the payoff of being a leader (PP) meets the waiting to enter option. However, since $T<M$, the platform firm would prefer to pre-empt at $T$ and the traditional will follow cross-entering at $F \cdot{ }^{15}$

In conclusion, with platform investment we can have 3 equilibria:

- Strong Strategic Advantage with entry: when the investment cost difference is large enough and uncertainty is low, the platform firm gains the option to behave as a monopolist on the cross-entry option and it can disregard the risk of an entry as leader by the competitor. Hence the platform firm cross-enters at $\theta_{m}^{*}$ and the traditional firm at $\theta_{T}^{* *}$.

- Strong Strategic Advantage with no entry: the platform firm has the option to behave to behave as a monopolist on entry, but at the same time has no incentive to cross-enter because the payoff is not high enough. The outcome is a parallel monopoly with no entry

- Weak Strategic Advantage: when the investment cost difference is not so large, the platform firm faces a cross-entry threat of the traditional firm before its optimal timing of entry, $\theta_{M}^{*}$. Hence, the platform firm enter much earlier than it would like: it enters just before $\theta$ reaches $\theta_{T}^{*}$, inducing a later cross-entry by the competitor at $\theta_{T}^{* *}$.

\footnotetext{
${ }^{15}$ Note that given the dynamic setting and the asymmetric investment cost, we have only this equilibrium: though the payoff of preempting is lower than remaining in parallel monopoly, the power of the platform firm rules out any kind of doubts on any other equilibria as it is instead in the static setting of Fudenberg and Tirole (1985).
} 


\section{Volatility analysis}

We now investigate the impact of demand volatility on the value of the platform at the point of entry. Note that because of convexity of profits in demand, expected profits increases with demand uncertainty. This encourages entry, which produces additional convex payoffs from the capture of market share in the other segment. However, also the value of the waiting to invest option increases with uncertainty.

We analyze first the impact of market volatility on the condition (19) that distinguishes between Strong (with and without entry) and Weak Strategic Advantage. We next analyze its impact on the expected profits in case of Strong Strategic Advantage with entry, with no entry and in case of Weak Strategic Advantage. Later we solve for the value of the platform investment and the impact of uncertainty.

The condition that distinguishes between the Strong Strategic Advantage and the Weak Strategic Advantage has a monotonic behavior in respect to market volatility. An increase in demand volatility increases the strategic advantage of the platform: with higher volatility, the platform firm can behave more often as a de facto monopolist on entry because the incentive to preempt for the traditional firm tends to diminish or vanish with higher the demand volatility. ${ }^{16}$

Concerning the condition that distinguish between entry and no entry in case of Strong Strategic Advantage the higher the demand uncertainty the less the platform firm has an incentive to cross enter and prefers to remain in a parallel monopoly.

These two conditions are represented in Figure 3

In case of Strong Strategic Advantage, we show that an increase in demand volatility induces platform firm to postpone cross-entry as it can behave de facto as a monopolist. Formally:

Proposition 7 An increase in demand uncertainty (defined as an increase in increase in $\mu$ holding the market drift constant) leads to a longer delay to entry on the platform firm.

\footnotetext{
${ }^{16}$ The only values of the investment ratio for which there can be a switch between Strong and Weak Strategic Advantage are between 0.44 and 0.63 ; for investment cost ratio higher than 0.63 platform firm has Weak Strategic Advantage; otherwise it has Strong Strategic Advantage.
} 
Proof.

$\frac{\partial \theta_{m}^{*}}{\partial \mu}=\frac{2 r I_{P}}{(L-M)} \frac{-(2 \mu-\alpha) \sqrt{\alpha^{2}+4 r(\mu-\alpha)}+2(r-\mu)(\mu-\alpha)+\alpha^{2}}{\sqrt{\alpha^{2}+4 r(\mu-\alpha)}\left(\sqrt{\alpha^{2}+4 r(\mu-\alpha)}+\alpha-2 \mu\right)^{2}}$

which can be seen after some tedious calculations to be always positive.

This is also valid in the case of the optimal timing of entry as a follower by the traditional firm entry.

It follows also that the payoff of the platform firm to cross-enter is also positively related to uncertainty. ${ }^{17}$

The impact of market uncertainty on cross-entry thresholds and the present value of the expected profits is shown in Fig.4.

Under Weak Strategic Advantage, a change in profit volatility can have either a positive or negative effect on the cross-entry threshold.

There are three elements that effects cross-entry in different way. The higher the uncertainty, the higher is the option value to be a follower; at the same time, also the payoff to be a leader is higher due to the endogenous convexity of the profits. The third element is the behavior of the competitor as follower: the higher the uncertainty, the higher the entry threshold of the follower, which allows the platform to enjoy asymmetric profits for a longer time (i.e. until a higher demand levels is reached).

The total effect of uncertainty on $\Delta_{T}$ cannot be studied analytically. However simulations shows that the effect of uncertainty on $\Delta_{T}$ (i.e. on the demand threshold of entry and the present value of the profits of the platform firm) is not monotonic. In particular, the effect depends on the different investment cost ratio, our measure of the strategic advantage gained by the platform investment. The results are summarized in Figure 5, 7, 8 and 6 .

The economic interpretation of these figures is based on the fact that under weak strategic advantage, the behavior of the platform firm is driven by the concrete threat of entry of the traditional firm.

When the strategic advantage is not very high, the threat of preemption of the traditional firm is monotonic in respect to demand volatility: the higher the

\footnotetext{
${ }^{17}$ The payoff of the platform firm to cross-enter is constituted by the present value of the expected profits in parallel monopoly plus the option to enter in the market of the incumbent. The present value of the first profits stream is positively related to uncertainty. It can be shown instead that the entry option is in general positively related to uncertainty, except for very high uncertainty values for which the option value is negatively related. The total effect of these two components on the present value of the expected profit is positive.
} 
uncertainty the earlier the platform firm is forced to exercise its entry option. This is because of the higher expected profit from entry, since the potential losses avoided by waiting to invest are less convex than the potential higher gains under entry. By Jensen's inequality, a mean-preserving increase in uncertainty favors investment in the strategic growth option over the waiting option. This behavior recalls the results in a static setting: the higher profit convexity leads to a greater increase in the value of the entry option relative to the waiting to invest option (Kulatilaka and Perotti (1998)).

When instead the investment ratio is somewhat lower i.e. under Weak Strategic Advantage), entry behavior is not monotonic. When uncertainty is low, as uncertainty increases, the relative stability of the demand level induces the traditional firm to wait longer to enter in exchange of higher demand levels. For high uncertainty levels, the traditional firm gives more weight on the time interval in which enjoys asymmetric profits rather than on the demand level: in this case the expected period time increases, because the follower waits longer before cross entering and because the traditional firm enters earlier (see Fig.5 and 6).

This reasoning can also explain the non-monotonicity of the present value of the profits with respect to demand volatility: for low uncertainty levels the present value increases while it decreases for high uncertainty. Figure 7 shows the platform value for different investment cost ratios. The shape of the curves is a direct consequence of the expected time of asymmetric profits for the platform. This can be seen comparing Figure 7 and 8 .

Note that as a direct consequence of the entry strategy of the traditional firm, the expected period of asymmetric profit for the platform firm is constant in respect to the investment ratio.

The last step of the volatility analysis is the analysis of the condition that distinguishes between the Strong Strategic Advantage and the Weak Strategic Advantage. As it can be seen from Figure ??, an increase in demand volatility increases the strategic advantage of the platform: with higher volatility, the platform firm can behave more often as a de facto monopolist on entry because the incentive to preempt for the traditional firm tends to diminish or vanish with higher the demand volatility. ${ }^{18}$

\footnotetext{
${ }^{18}$ The only values of the investment ratio for which there can be a switch between Strong and Weak Strategic Advantage are between 0.44 and 0.63 ; for investment cost ratio higher
} 


\section{The Value of the Platform}

Until now we have assumed that the incumbent has a traditional technology, which the platform is developed by an innovating firm.

But what is the ex-ante value of a platform? When would it be convenient to build for an innovative firm a platform rather than making a conventional entry?

We first compute the value of the option to acquire the platform (i.e. the value of the underlying technology) and later we compute for which platform cost the innovative firm finds convenient to buy the platform (i.e. the right to produce with the platform). Finally, we consider when it would start production immediately, or wait for a later optimal time to start the production.

\section{V.1 Strong Strategic Advantage}

We analyze what demand value a new firm with a platform would enter in the first market segment, and subsequently when it would acquire a platform. As the traditional firm is an incumbent in one market segment, the platform firm finds convenient to avoid direct competition and will enter initially on the other market segment available. ${ }^{19}$

We first compute the platform value in case of strong strategic advantage with entry and later in case of no entry.

In case of strong strategic advantage with entry computing the platform value and when the innovative firm would enter in the first market segment means computing the value of an American compound option and its exercise threshold. The calculations of this follows the similar steps of Appendix A.3. The compound option value is of the type:

$$
V_{S}=O_{1, S} \theta^{\beta}
$$

than 0.63 platform firm has Weak Strategic Advantage; otherwise it has Strong Strategic Advantage.

${ }^{19}$ It can be demonstrated that either in strong or weak strategic advantage the platform firm would never prefer to enter at first in the same market where the incumbent is, though this would allow to enjoy asymmetric profits for longer time. However, this longer period of asymmetric profit do not compensate for the lower profit flow during the first part of the game when the two firms compete in the same market. 
The constant term, $O_{1, S}$, is given by:

$$
O_{1, S}=O_{M}+\theta_{1, S}^{-\beta+1} \frac{M}{\beta(r-\mu)}=O_{M}+\theta_{1, S}^{-\beta} \frac{I_{P}}{\beta-1}
$$

where $O_{M}$ is given by (see Appendix A.3 for the relative calculations):

$$
O_{M}=\frac{L-M}{\theta_{m}^{* \beta-1} \beta(r-\mu)}-\frac{L-D}{\theta_{T}^{* *^{\beta-1}}(r-\mu)}
$$

It follows that optimal entry threshold will be in correspondence of the following $\theta$, that we define $\theta_{1, S}$ :

$$
\theta_{1, S}=\frac{I_{P}(r-\mu)}{M} \frac{\beta}{\beta-1}
$$

It is now possible to calculate the demand threshold to acquire a platform. We assume that a platform can be built only by one firm. We do not describe this initial "race to the platform". We also rule out the possibility that the incumbent firm is capable to build the platform. An informal argument is that a traditional firm would not build a platform just to enter in the second market, as it has to incur higher overall investment costs. A new firm would buy a platform as a technology to produce both products, so it finds convenient to invest in the platform for lower demand values than the incumbent firm.

This is a different situation than in a classical real option investment environment: there are many firms that have the opportunity to invest and hence all firms compete under perfect competition to buy the right (the unique technology) to build the platform. The option to acquire the platform will be exercised as soon as the expected profits are above the investment costs, that is when $\theta$ reaches $\theta_{0, S}$ :

$$
\theta_{0, S}=\left(\frac{K}{O_{1, S}}\right)^{\frac{1}{\beta}}
$$

where $K$ is the investment costs of the platform. ${ }^{20}$

\footnotetext{
${ }^{20}$ Inverting equation $(29)$, it can be also determined how much an innovative firm would invest in a platform for each demand level.
} 
The innovative firm will acquire the platform as soon as the initial market demand reaches a threshold $\theta_{0, S}$ (which is smaller than $\theta_{1, S}$ ), such the investment cost is less than the platform value:

$$
K<O_{M} \theta_{1, S}^{\beta}+\frac{I_{P}}{\beta-1}
$$

At this point the firm will find convenient to invest in the platform, although not necessary yet to enter in the first market.

When demand parameters (e.g. low drift, low uncertainty, high discount rate, low product differentiation) are such that condition (30) is not verified (i.e. $K>O_{M} \theta_{1, S}^{\beta}+\frac{I_{P}}{\beta-1}$ ), a new firm will invest in the platform and in the first product simultaneously.

As we can see, the higher is the demand volatility, the less stringent is this condition. In a highly volatile market the firm prefers to guarantee for itself a strategic advantage by acquiring the platform, and at the same time it waits longer for a better market situation to become active in the market. The impact of uncertainty on the platform value (measured by the reciprocal of $\beta$ ) is unambiguously positive.

In case of Strong Strategic Advantage with no entry, the platform value is given by the present value of the profit in parallel monopoly: $\frac{M}{r-\mu}$.

\section{V.2 Weak Strategic Advantage}

In case of weak strategic advantage, the entry cost difference between the traditional and the platform firm is not so large. Following the same steps for the other case it can be shown that the platform value can be computed and is given by:

$$
V_{W}=O_{1, S} \theta^{\beta}
$$

where $^{21}$ :

\footnotetext{
${ }^{21}$ This constant is positive when $\frac{I_{P}}{I}<\left(\frac{M}{L-D} \frac{1}{\beta}\right)^{\frac{1}{\beta-1}} \frac{M}{D-F}$. This is always true since $1<$ $\left(\frac{M}{L-D} \frac{1}{\beta}\right)^{\frac{1}{\beta-1}} \frac{M}{D-F}$ and given the assumption on the investment costs.
} 


$$
O_{1, W}=\frac{I_{P}}{\beta-1} \theta_{1, W}^{-\beta}+\left(\frac{1}{\theta_{T}^{*}}\right)^{\beta}\left(\frac{L-M}{r-\mu} \theta_{T}^{*}-I_{P}\right)-\frac{L-D}{r-\mu}\left(\frac{1}{\theta_{T}^{* * *}}\right)^{\beta-1}
$$

The entry threshold to enter in the first product for a firm which has already acquired the platform is:

$$
\theta_{1, W}=\frac{I_{P}(r-\mu)}{M} \frac{\beta}{\beta-1}
$$

that is at the same demand threshold as $\theta_{1, S}$ (see equation (26).

We can now calculate when it is convenient to invest in the platform. The $\theta$ value for which it is convenient to enter is given by:

$$
\theta_{0, W}=\left(\frac{K}{O_{1, W}}\right)^{\frac{1}{\beta}}
$$

The platform firm will invest in the platform before entering in the first market segment, when $\theta_{0, S}$ is smaller than $\theta_{1, S}$, that is when:

$$
K<\frac{I_{P}}{\beta-1}+\left(\frac{\theta_{0, W}}{\theta_{T}^{*}}\right)^{\beta}\left(\frac{L-M}{r-\mu} \theta_{T}^{*}-I_{P}\right)-\frac{L-D}{r-\mu} \theta_{0, W}\left(\frac{\theta_{0, W}}{\theta_{T}^{* *}}\right)^{\beta-1}
$$

otherwise it will invest in the platform and in the first product simultaneously. ${ }^{22}$

This condition is more stringent than the one of the Strong Strategic Advantage.

After tedious calculations, it can be shown that the higher is the volatility, the higher is the value of the platform. The more demand is volatile, the more the firm tends to wait to invest in the platform, while at the same time it become more attractive to secure control of the platform for itself even without the immediate profits of the first product. We plan in future to work to analyze the case of competition across platforms.

\footnotetext{
${ }^{22}$ We abstract here from he possibility of the traditional firm entering both market segments in order to pre-empt entry.
} 


\section{Conclusions}

We have considered a strategic logistic investment under dynamic uncertainty on future consumer demand. An innovative firm acquires a productive and distributive platform to gain superior entry advantages. We study the subsequent entry decision in specific products and compute the value of the option to wait to invest against the (temporarily) higher profits of immediate entry. We can rationalize a much greater value for platform firms relative to traditional producers, especially over market size.

Investing in a platform means acquiring a "strategic cross-entry option", a concept related to the "strategic growth option" (Kulatilaka and Perotti (1998)). On the other hand, platform investment involves absorbing significant demand uncertainty. Therefore, the value of not committing funds to platform investment increases with demand uncertainty. The most striking result we obtain is that in general, in a regime of higher volatility of demand, platform strategic advantage increases. In fact platform firm may ends up "controlling" the entry options, and behaving more as a de facto monopolist. In our context, greater uncertainty means greater risk but also greater opportunities thanks to the early (cross-)entry advantage gained by acquiring the platform.

Platform investment turns out to have several strategic effects. It may grant a competitive advantage to enter earlier in competitors' market segments; but

it also eliminates the possibility of simultaneous entry and may help avoiding undesirable "excessive" competition equilibria.

Our surprising results in the positive effect of uncertainty on the value of investment are driven by the oligopolistic market structure. Firms with market power respond to higher demand by increasing both output and prices; therefore, profits are endogenously convex in demand. High volatility gives more weight to potential high profits than to the possibility to suffer losses due to low demand. Since the potential losses avoided by waiting to invest are less convex than the potential gains from entry, more uncertainty (in the sense of a mean-preserving spread in demand) reduces the threshold of expected future demand at which the firm finds attractive to enter, and increases the value of the entry options relative to the waiting to invest option

A current drawback is the very simplified notion of platform we have adopted. In the next version we wish to model both a multidimensional platform as well 
as the initial decision on the size of the platform. Moreover, a broader platform may allow entrance in unrelated market segments without cross-effects. In case of internet websites, the analysis of an horizontal portal imply a greater dimensionality of the set of strategic entry options and thus a correspondingly higher value for a platform firm relatively to a traditional producer. We plan to develop a more specific interpretation for internet portals in future work.

Intuitively, the optimal platform size (which is related to the potential range of differentiated products) depends on the fact that the greater is the initial differentiation, the weaker are the cross-price effects. The firm in charge of the platform may become dominant in some products as later Innovators face either higher entry costs or a time disadvantage relative to the platform-owner, and may choose therefore a more limited range of entry among products. The outcome of this decision is not trivial, as it depends on product features and expected market demand evolution.

\section{References}

Baldwin, C. Y., and K. Clark (2000): Design Rules: The Power of Modularity. The MIT Press, Cambridge, Massachusetts.

Dixit, A. (1980): "The Role of Investment in Entry Deterrence," The Economic Journal, 90(3), 95-106.

Dixit, A. K., And R. P. Pindyck (1994): Investemnt under Uncertainty. Princeton University Press, Princeton, New Jersey.

Fudenberg, D., and J. Tirole (1985): "Preemption and Rent Equalization in the Adoption of New Techonology," Review of Economic Studies, 52(3), 383-401.

Grenadier, S. (1996): "The Strategic Exercise of Options: Development cascades and Overbuilding in Real Estate Markets," The Journal of Finance, 51(5), 1653-1679.

Harrison, J. (1985): Brownian Motion and Stochastic Flow Systems. John Wiley and Sons, New York.

Huisman, K., and P. Kort (1999): "Effects of Strategic Interactions on the Option Value of Waiting," Discussion Paper 9992, Discussion Paper CentER,. 
Khanna, N., and S. Tice (2000): "Strategic Response of Incumbents to New Entry: The Effect of Ownership Structure, Capital Structure, and Focus," The Review of Financial Studies, 13(3), 749-779.

Klemperer, P. (1995): "Competition when Consumers have Switching Costs: An Overview with Applications to Industrial Organization, Macroeconomics, and International Trade," The Review of Economic Studies, 62(4), 515-539.

Kogut, B., and N. Kulatilaka (1994): "Options Thinking and Platform Investment: Investing in Opportunity," California Management Review, 36(2), $52-71$.

Kulatilaka, N., and E. Perotti (1998): "Strategic Growth Options," Management Science, 44(8), 1021-1031.

(forthcoming 2000): "Time-to-Market Capability as Stackelberg Growth Option," Discussion paper.

Lambrecht, B. M., and W. Perraudin (1997): "Real Option and Preemption," Discussion paper.

(1999): "Real Options and Pre-emption under incomplete information," Discussion paper.

McDonald, R., and D. Siegel (1986): "The Value of Waiting to Invest," Quarterly Journal of Economics, 101(4), 707-728.

Rotschild, M., and J. Stiglitz (1970): "Increasing Risk I: A Definition," Journal of Economic Theory, (2), 225-243.

Smets, F. (1991): "Exporting versus FDI: The Effect of Uncertainty, Irreversibilities and Strategic Interactions," Discussion paper.

\section{A Appendixes}

\section{A.1 Competition analysis}

\section{A.1.1 Parallel monopoly}

Consider first the case when both firms are monopolist in one market. They will choose their output taking into account the impact of the output by the 
other firm on its own marginal profitability. We assume that firm $i$ is active in market 1 and firm $j$ in market 2. The profit maximization problem for firm $i$ can be summarized as follows:

$$
\operatorname{Max}_{q_{1 i}}\left(p_{1} q_{1 i}\right)=\operatorname{Max}_{q_{1 i}}\left[\sqrt{\theta}-\left(q_{1 i}+q_{1 j}\right)-a\left(q_{2 i}+q_{2 j}\right)\right] q_{1 i}
$$

Firm $j$ has a symmetric profits maximization problem. The outcome of the game is symmetric:

$$
\begin{gathered}
q_{1 i}=q_{2 j}=\frac{\sqrt{\theta}}{a+2} \\
p_{1}=p_{2}=\frac{\sqrt{\theta}}{a+2} \\
\prod_{i}=\prod_{j}=\frac{\theta}{(a+2)^{2}} \equiv M \theta
\end{gathered}
$$

The expected present value of all future profits as $t$ goes to infinity is given by:

$$
E\left[\int_{0}^{\infty} M \theta e^{-r t} d t\right]=\frac{M}{r-\mu} \theta
$$

Notice that this coincide with the classic constant growth valuation model.

\section{A.1.2 Duopoly in both markets (parallel duopoly)}

We consider now the case when both firms are active in both markets. The outcome of the game in this case is symmetric:

$$
\begin{aligned}
q_{1 i} & =q_{1 j}=q_{2 i}=q_{2 j}=\frac{1}{3} \frac{\sqrt{\theta}}{a+1} \\
p_{1} & =p_{2}=\frac{1}{3} \sqrt{\theta}
\end{aligned}
$$

Note that prices are the same, as in the classic Cournot outcome; however, quantities are lower as firms take into account the demand cross effect (which is increasing in $a$ ). 
Profits are also symmetric and decreasing in $a$ :

$$
\prod_{i}=\prod_{j}=\frac{2}{9} \frac{\theta}{a+1} \equiv D \theta
$$

for an expected present value equal to:

$$
E\left[\int_{0}^{\infty} D \theta e^{-r t} d t\right]=\frac{D}{r-\mu} \theta
$$

\section{A.1.3 Asymmetric competition}

The last case is where in market 1 we have a duopoly while in market 2 we have a monopoly; firm $j$ is in both products while (firm $i$ ) is only in the first one.

The strategic output choice of this asymmetric competition is:

$$
\begin{aligned}
q_{1 i} & =\frac{1}{3} \sqrt{\theta} \\
q_{1 j} & =\frac{1}{6} \frac{2-a}{1+a} \sqrt{\theta} \\
q_{2 j} & =\frac{1}{2} \frac{\sqrt{\theta}}{a+1}
\end{aligned}
$$

which results in differentiated prices:

$$
\begin{aligned}
& p_{1}=\frac{1}{3} \sqrt{\theta} \\
& p_{2}=\frac{\sqrt{\theta}}{2}\left(1-\frac{a}{3}\right)
\end{aligned}
$$

Note that prices in the monopolized product (product 2) equal the monopoly price even, though there is a cross effect. The reason is that the firm $j$ which

is monopolist in the other product chooses to produce less than the Cournot amount of product 1 to keep up profits in the segment it controls. The resulting profit levels for the firm $j$ in both product equal:

$$
\begin{aligned}
& \prod_{1 j}=\frac{1}{9} \theta \\
& \prod_{2 j}=\frac{1}{36} \theta(a-3) \frac{a-2}{1+a}
\end{aligned}
$$


For the firm present in both markets, the sum of the profit flow from the two markets is given by:

$$
\prod_{N}=\frac{1}{36} \frac{13-5 a}{1+a} \theta \equiv L \theta
$$

and its present value is:

$$
E\left[\int_{0}^{\infty} A \theta e^{-r t} d t\right]=\frac{L}{r-\mu} \theta
$$

The other firm earns:

$$
\prod_{i}=\frac{1}{9} \theta \equiv F \theta
$$

Thus the expected present value is:

$$
E\left[\int_{0}^{\infty} L \theta e^{-r t} d t\right]=\frac{F}{r-\mu} \theta
$$

Notice also that the equilibrium value of $p_{1}$ is the same as in the classical Cournot duopoly. This means that in terms of expected profit margins firm $i$ is indifferent whether the other firm is present in the other market or not.

Note finally that when $a$ tends to 1 (minimum differentiation) the results tends to correspond to the classical Cournot case, while if it tends to 0 (maximum differentiation) they tend to the classical monopoly case.

\section{A.2 Timing of entry}

We first demonstrate that the firm with the platform is entering before if the competitor has not invested in the platform.

If the curve of the threshold value for the asymmetric case is always above the one for the asymmetric case where both firms have invested in the platform, this implies that the leader with the platform in the asymmetric case enters before than in the symmetric case.

Analytically this means that the following relation has to always verified: 


$$
\begin{aligned}
& \frac{L-F}{r-\mu} \theta-\frac{L-D}{r-\mu} \theta\left(\frac{\theta}{\theta_{T}^{* *}}\right)^{\beta-1}-\frac{D-F}{r-\mu} \theta\left(\frac{\theta}{\theta_{I}^{* *}}\right)^{\beta-1}-\left[1-\left(\frac{\theta}{\theta_{I}^{* *}}\right)^{\beta-1}\right] I_{P}- \\
& -\frac{L-F}{r-\mu} \theta+\frac{L-F}{r-\mu} \theta\left(\frac{\theta}{\theta_{I}^{* *}}\right)^{\beta-1}+\left[1-\left(\frac{\theta}{\theta_{I}^{* *}}\right)^{\beta-1}\right] I_{P}>0
\end{aligned}
$$

Rearranged:

$$
\frac{L-F}{r-\mu}\left(\frac{1}{\theta_{T}^{* *}}-\frac{1}{\theta_{I}^{* *}}\right)>0
$$

This is always negative because $\theta_{T}^{* *}>\theta_{I}^{* *}$.

Due to the difference in the investment costs between the platform and the non platform investment when the firms have invested both in the platform the leaders enters before than when they have invested in non platform. This implies that the firm with the platform will be the leader in the when the two firms have invested differently and will invests before than in the case both firms have platform or have no platform.

\section{A.3 Strategic entry value of a monopolist entry option}

We want to demonstrate that when the firms cross-enters as soon as it prefers to be a leader rather than a follower, it enters always before than a firm with similar features but with the monopoly on the option to cross-enters. To demonstrate this we first calculate the option value and the threshold $\theta$ of the option if the firm with platform has the monopoly to enter in the second market as first. Second we see when it has economic sense for the firm with the monopoly to ever cross-enters and finally we compare this with the case in which the firm cross enters as soon as it is convenient for her to be a leader.

As the firm has the monopoly to enter in the second market, the solution is found solving a similar differential equation as in Dixit and Pindyck (1994), but with slightly different value matching and smooth pasting condition. In this case in fact we have to take into account the fact that at $\theta_{T}^{* *}$ the other firm cross-enters. So the new differential equation and its conditions are:

$$
\frac{1}{2} \sigma^{2} \theta^{2} G^{\prime \prime}(\theta)+\mu \theta G^{\prime}(\theta)-r G(\theta)+M \theta=0
$$




$$
\left\{\begin{array}{l}
G(0)=0 \\
G\left(\theta_{m}^{*}\right)=O_{M} \theta_{m}^{*^{\beta}}+M \frac{\theta_{m}^{*}}{r-\mu}=\frac{L \theta_{m}^{*}}{r-\mu}\left[1-\left(\frac{\theta_{m}^{*}}{\theta_{T}^{* *}}\right)^{\beta-1}\right]+\left(\frac{\theta_{m}^{*}}{\theta_{T}^{* *}}\right)^{\beta} \frac{D}{r-\mu} \theta_{T}^{* *}-I_{P} \\
G^{\prime}\left(\theta_{m}^{*}\right)=\beta O_{M} \theta_{m}^{*^{\beta-1}}+\frac{M}{r-\mu}=\frac{L}{r-\mu}\left[1-\beta\left(\frac{\theta_{m}^{*}}{\theta_{T}^{* *}}\right)^{\beta-1}\right]+\beta\left(\frac{\theta_{m}^{*}}{\theta_{T}^{* *}}\right)^{\beta-1} \frac{D}{r-\mu}
\end{array}\right.
$$

It follows that the option value is given by $O_{A} \theta^{\beta}$ and the threshold value is given by $\theta_{m}^{*}$ where:

$$
\begin{aligned}
\theta_{m}^{*} & =\frac{\beta}{\beta-1} \frac{I_{P}(r-\mu)}{L-M} \\
O_{M} & =\frac{L-M}{\theta_{m}^{* \beta-1} \beta(r-\mu)}-\frac{L-D}{\theta_{T}^{* *^{\beta-1}}(r-\mu)}
\end{aligned}
$$

$O_{M}$ can be negative. Substituting the entry values and rearranging $O_{M}$ becomes:

$O_{M}=\frac{I_{P}}{\beta-1}\left[(L-M)^{\beta}-\beta(L-D)(D-F)^{\beta-1}\left(\frac{I_{P}}{I}\right)^{\beta-1}\right]\left[I_{P}(r-\mu) \frac{\beta}{\beta-1}\right]^{-\beta}$

$O_{M}$ is then positive when the second term is positive, that is when:

$$
\frac{I_{P}}{I}<\left(\frac{1}{\beta} \frac{L-M}{L-D}\right)^{\frac{1}{\beta-1}} \frac{L-M}{D-F}
$$

the second term is always smaller than 1 the above condition is not always verified. However, this is not relevant for our model because for the interval of $\gamma$ we are interested in, the option plus the actualized profit give a positive value

\section{A.4 Pre-emptive entry by the platform firm}

In this Appendix we want to demonstrate that when the conditions for the strategic advantage are verified, $\theta^{m}=\frac{\beta}{\beta-1} \frac{I_{P}(r-\mu)}{A-M}$ is always smaller than when the traditional firm would enter as leader.

Similarly to (??) the traditional firm would enter when it prefers to be leader rather than a follower, that is when: 


$$
\Delta_{T}(\theta)=(L-F) \theta-\left(\frac{L-D}{\theta_{I}^{*^{\beta}-1}}+\frac{D-F}{\theta_{T}^{*^{\beta-1}}}\right) \theta^{\beta}-\left[1-\left(\frac{\theta}{\theta_{T}^{* *}}\right)^{\beta}\right] I(r-\mu)=0
$$

We want then to see when $\Delta_{T}\left(\theta_{m}\right)$ is positive or negative. We express the above condition in terms of the investment ratio:

$$
\Delta_{T}\left(\theta_{m}\right)=\frac{\beta}{\beta-1} \frac{L-F}{L-M}-\frac{\beta}{\beta-1}\left(\frac{D-F}{L-M}\right)^{\beta}\left[\frac{L-D}{D-F}+\frac{1}{\beta}\left(\frac{I}{I_{P}}\right)^{\beta-1}\right]-\frac{I}{I_{P}}
$$

First of all, when $\frac{I_{P}}{I}$ tends to zero, $\Delta_{T}\left(\theta_{m}\right)$ tend to minus infinity and the platform firm would enter before the traditional firm.

Second it can be noticed that the first two parts of $\Delta_{T}\left(\theta_{m}\right)$ is always smaller than 1 while the second is always bigger than 1 . It follows that $\Delta_{T}\left(\theta_{m}\right)$ is always negative. Since there are no values of the ratio $\frac{I_{P}}{I}$ for which $\Delta_{T}\left(\theta_{m}\right)$ is positive, platform firm when it has the monopoly to enter is entering always before the traditional firm would enter strategically. 


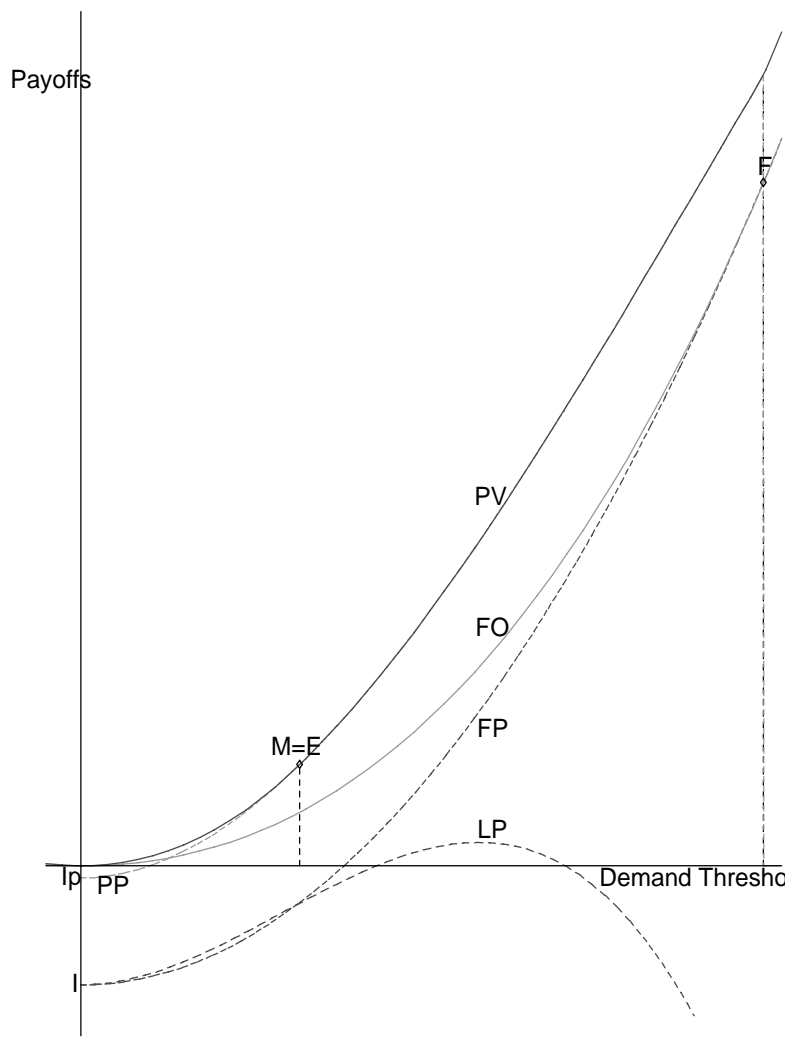

Figure 1: Strong Strategic Advantage entry strategies. ( $\mathrm{PV}=$ Platform Value, $\mathrm{PP}=$ Platform Pay-off, $\mathrm{LP}=$ Leader Pay-off of the traditional firm, $\mathrm{FO}=$ Follower Option of the traditional firm, $\mathrm{FP}=$ Follower Pay-off of the traditional, $\mathrm{E}=$ Entry of the platform, $\mathrm{M}=$ Entry of the platform in case of Monopoly, $\mathrm{T}=$ Threat of traditional firm entry, $\mathrm{F}=$ Traditional Firm Entry as Follower $),(\sigma=0.3$, $\left.\mu=0.01, r=0.05, I=100, I_{P}=10, a=0.125\right)$. 


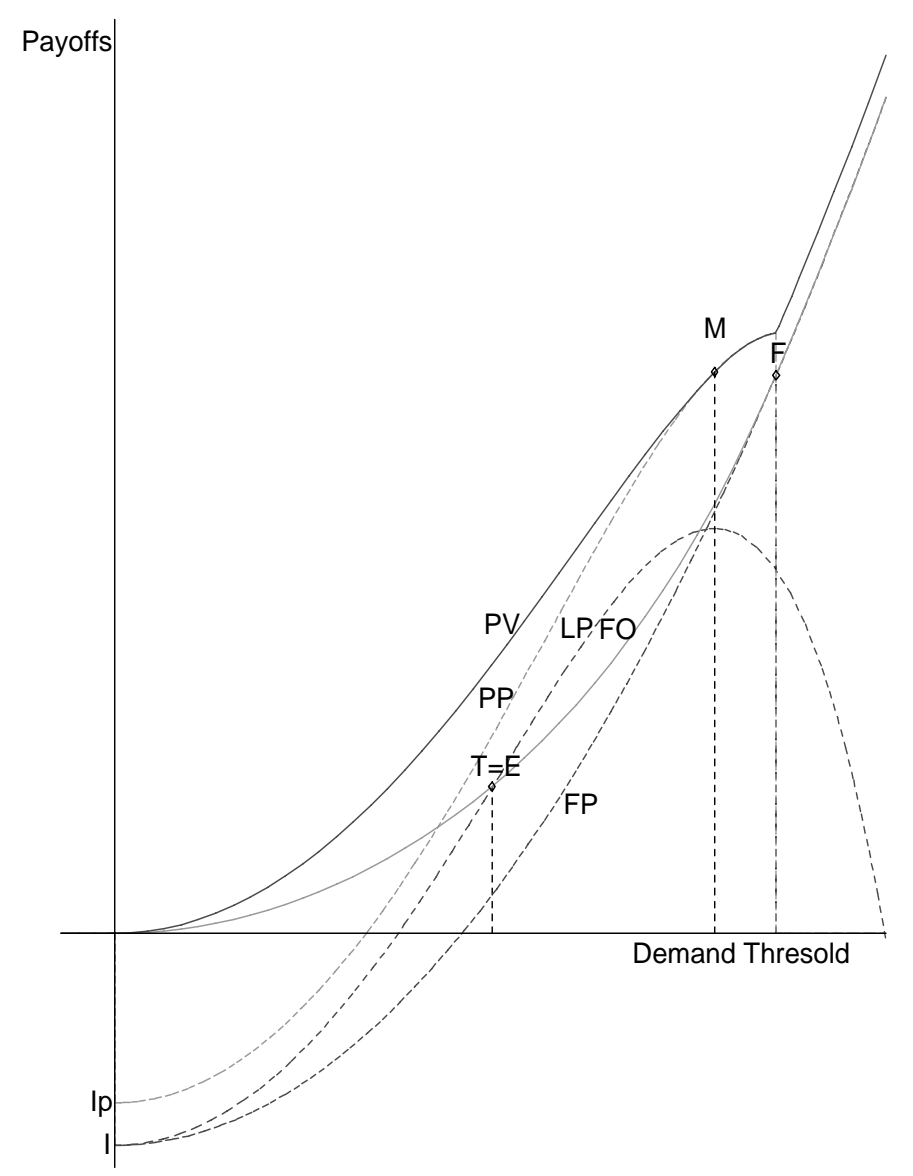

Figure 2: Entry strategies under Weak Strategic Advantage (PV=Platform Value, $\mathrm{PP}=$ Platform Pay-off, $\mathrm{LP}=$ Traditional firm Payoff as Leader, $\mathrm{FO}=$ Follower Option of the traditional firm, $\mathrm{FP}=$ Follower Payoff of the traditional firm, $\mathrm{E}=$ Entry of the Platform firm, $\mathrm{T}=$ Threat to entry of the traditional firm, $\mathrm{M}=$ Entry of the Platform in case of Monopoly, $\mathrm{F}=$ Traditional Firm Entry as Follower), $\left(\sigma=0.3, \mu=0.01, r=0.05, a=0.125, I=100, I_{P}=80\right)$ 


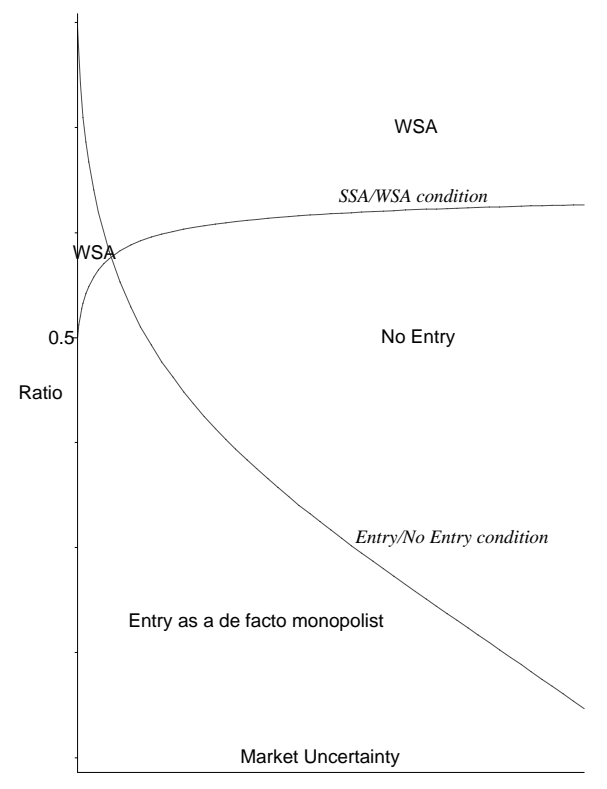

Figure 3: Effect of uncertainty on the condition of strong/weak strategic investment and the condition for entry and no entry. 


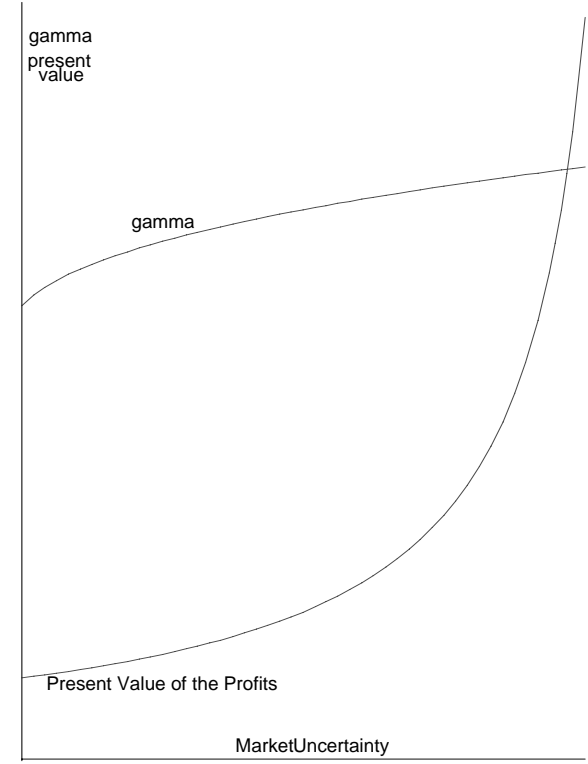

Figure 4: How the entry threshold and present value of the expected profits change with demand volatility (under Strong Strategic Advantage). 


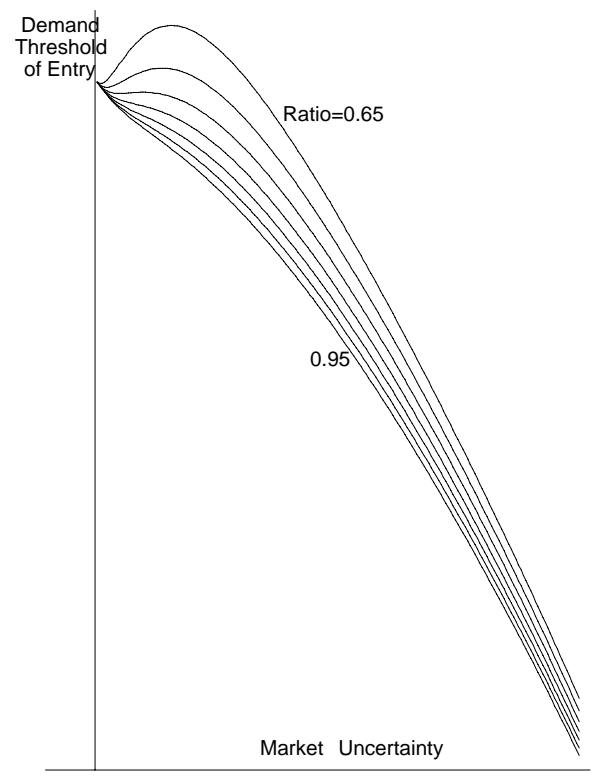

Figure 5: Entry threshold for a platform firm and uncertainty in case of Weak Strategic Advantage for different ratio values. 


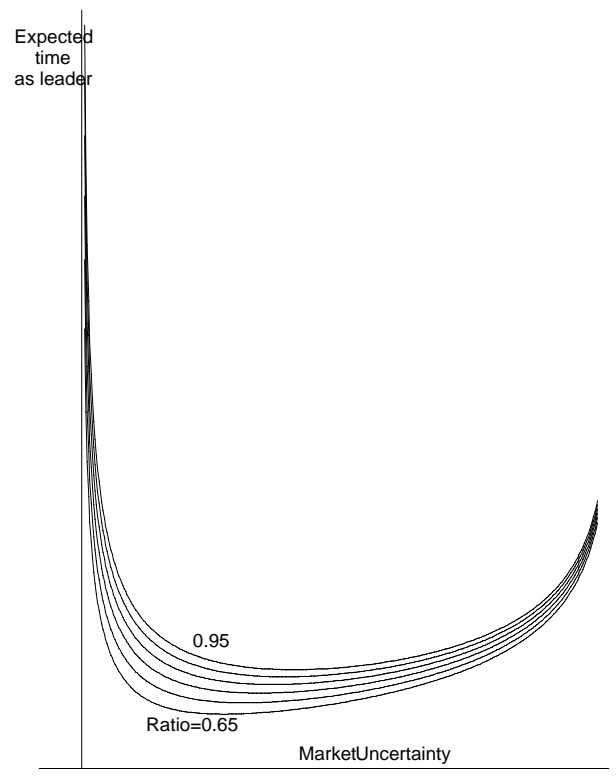

Figure 6: Expected period of asymmetric profits for the traditional firm as first entrant. 


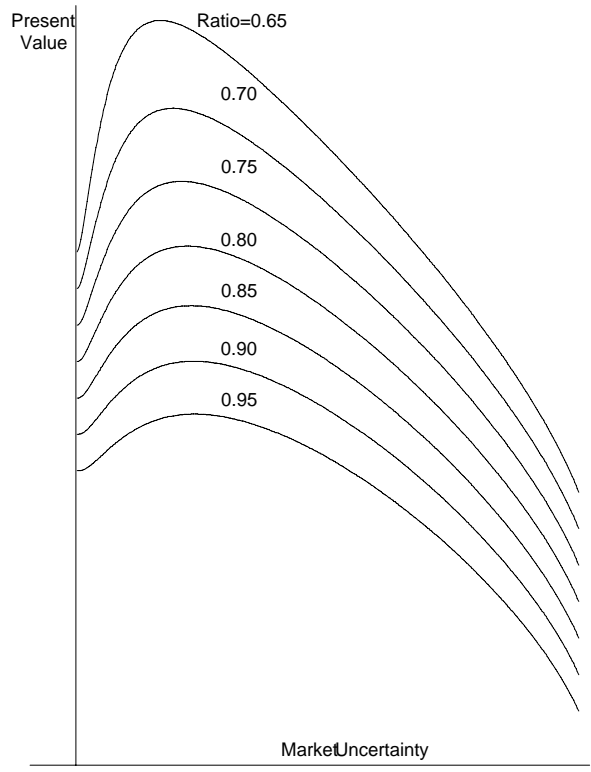

Figure 7: Present value at entry point of the platform firm investment ratio values (weak strategic advantage). 


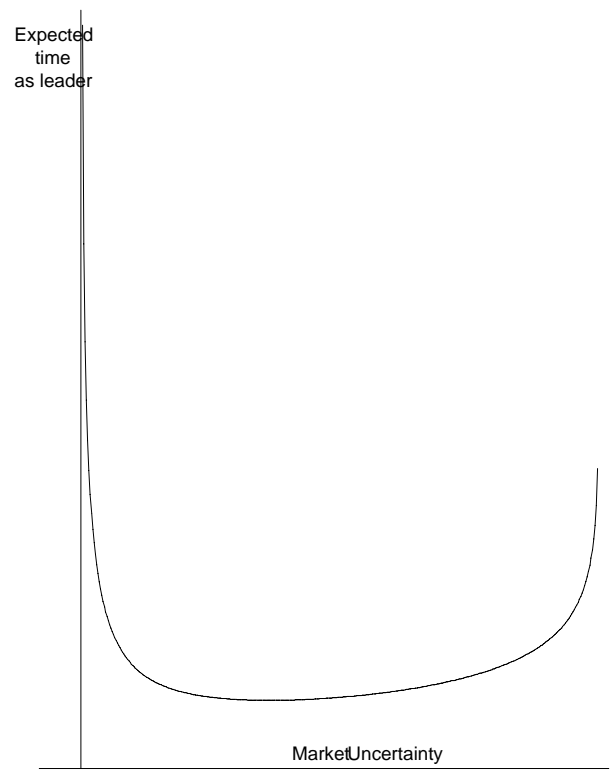

Figure 8: Expected period of asymmetric profits for the platform firm as first entrant. 